\title{
RELAC̣ÕES ENTRE ARGUMENTAÇ̃̃O E MODELAGEM NO CONTEXTO DA CIÊNCIA E DO ENSINO DE CIÊNCIAS
}

\author{
Rosária Justi* \\ Universidade Federal de Minas Gerais
}

RESUMO: Considerando a relevância de se promover um Ensino de Ciências autêntico, enfatizamos, neste trabalho, duas práticas epistêmicas que podem contribuir para este: a argumentação e a modelagem. Tais práticas e alguns dos principais elementos envolvidos nelas são caracterizados teoricamente. Essa caracterização sustenta a reanálise de um conjunto de dados empíricos a partir da qual propomos relacionamentos entre ações envolvidas em várias etapas da modelagem e habilidades argumentativas utilizadas na realização destas. Tais relacionamentos são inéditos na literatura e, ao mesmo tempo em que reafirmam a indissociabilidade entre as práticas epistêmicas científicas de argumentar e modelar, abrem novas frentes de investigação.

Palavras-chave: Ensino de Ciências autêntico. Modelagem. Argumentação.

\section{RELACCIONES ENTRE ARGUMENTACIÓN Y MODELAJE EN EL CONTEXTO DE LA CIENCIA Y DE LA ENSEÑANZA DE LAS CIENCIAS}

RESUMEN: Considerando la relevancia de promover una enseñanza de Ciencias autentica, destacamos, en este trabajo, dos prácticas epistémicas que pueden contribuir en este propósito: la argumentación y la modelaje. Tales prácticas y algunos de los principales elementos involucrados en ellas son caracterizados teóricamente. Esa caracterización sostiene el re-análisis de un conjunto de datos empíricos a partir del cual propusimos relacionamientos entre acciones involucradas en varias etapas de la modelaje y habilidades argumentativas utilizadas en la realización de ellas. Tales relacionamientos son inéditos en la literatura y, al mismo tiempo en que reafirman la incapacidad de disociar prácticas epistémicas científicas de argumentar y modelar, abren nuevas frentes de investigación.

Palabras clave: Enseñanza de las Ciencias auténtica. Modelaje. Argumentación. 
RELATIONS BETWEEN ARGUMENTATION AND MODELLING IN SCIENCE AND SCIENCE EDUCATION CONTEXTS

ABSTRACT: Assuming the relevance of promoting an authentic science teaching, two epistemic practices that may contribute to it are emphasised in this paper: argumentation and modelling. Such practices, as well as some of their main elements, are theoretically characterised. This categorisation supports the reanalysis of a set of empirical data from which we propose relations between the actions involved in each of the modelling stages and the argumentative skills used when they are performed. Such relations are novel in the literature. They reaffirm the inseparability of modelling and argumentation in science and in science education, and, at the same time, open new investigative fronts.

Keywords: Authentic science teaching. Modelling. Argumentation. 


\section{INTRODUÇÃO}

Caracterizar "ciência" é uma tarefa árdua à qual têm se dedicado inúmeros estudiosos com formações em áreas diferenciadas como, por exemplo, filosofia, história, sociologia etc. Apesar de reconhecer a amplitude desses estudos e a consequente existência de múltiplas visões, julgo importante explicitar algumas características gerais da ciência que contribuem para contextualizar a presente discussão.

- Ciência é um empreendimento humano, isto é, ela não é algo que existe à espera de ser descoberto, mas é produzida a partir de inúmeros procedimentos criados pela mente humana. Como tal, ela tem elementos de subjetividade e não conduz a verdades absolutas.

- Ciência é motivada pela curiosidade de entender o mundo, isto é, ela existe a partir da elaboração de questões relevantes e da análise crítica das evidências disponíveis e das ideias produzidas para interpretá-las.

- Oprincipal objetivo da ciência éproduzir conbecimento. Como os seres humanos, o mundo e os procedimentos para estudar cada um de seus aspectos estão em constante mutação, tanto o processo de construção de conhecimento quanto o seu produto - o conhecimento científico - são dinâmicos e não lineares.

Considerando apenas essas características, podemos afirmar que argumentação e modelagem são duas práticas epistêmicas importantes da ciência. Mas, para que tal afirmativa seja mais bem compreendida, precisamos explicitar nossa compreensão sobre essas práticas - tarefa da qual nos ocuparemos na próxima seção.

Por outro lado, assumindo que o contexto no qual estamos inseridos e que nos motiva a produzir conhecimento é o do Ensino de Ciências, julgamos igualmente importante destacar, neste momento, uma característica deste: a necessidade de que ele seja autêntico, isto é, de que seja o mais próximo possível da própria ciência. Para tanto, é essencial que o ensino:

- Envolva os processos pelos quais o conhecimento científico é produzido, é validado histórica e filosoficamente e é aceito socialmente;

- Reflita a centralidade da criatividade na ciência, que tem contribuído de forma ímpar para que ela seja um dos maiores empreendimentos humanos da atualidade;

- Apresente uma estrutura simples de ideias a partir das quais seja possível explicar satisfatoriamente os fenômenos observados e vivenciados no mundo; e

- Favoreça a proposição de soluções para questões básicas relacionadas ao bem-estar social e à saúde dos indivíduos (GILBERT, 2004).

Assim, a promoção de um Ensino de Ciências autêntico implica no envolvimento dos estudantes em práticas epistêmicas da ciência e no metaconhecimento sobre estas como estratégias para a aprendizagem de ciências (WHITE; FREDERIKSEN, 1998; CHINN; MALHOTRA, 2002; 
DUSCHL; ELLENBOGEN, 2009; CARAGNETTO, 2010; JIMÉNEZALEIXANDRE, 2012). A nosso ver, isso sintetiza todas as justificativas para a introdução de argumentação e modelagem em todos os contextos e níveis de Ensino de Ciências.

No presente trabalho, discutimos como essas práticas estão intimamente relacionadas e evidenciamos como o envolvimento em cada uma delas pode favorecer o desenvolvimento dos conhecimentos e das habilidades necessários para a realização da outra.

\section{EXPLICITANDO SIGNIFICADOS IMPORTANTES}

\section{Capacidades argumentativas}

Argumentação tem sido discutida a partir de várias perspectivas cuja adoção resulta em distintas frentes de trabalho na área de Ensino de Ciências. Tal discussão foge ao escopo deste trabalho ${ }^{1}$, mas é aqui mencionada para justificar a adoção de um referencial específico.

Neste trabalho, consideramos que argumento é uma afirmativa acompanhada de sua justificativa, sendo esta última sustentada por evidências (KUHN, 1991) e que argumentação consiste dos processos de elaborar e utilizar argumentos visando atingir três objetivos principais: atribuição de sentido (quando o sujeito tenta relacionar evidências e afirmativas), articulação de ideias (quando o sujeito tenta construir um argumento de forma que ele possa ser comunicado a outros) e persuasão (quando o sujeito tenta convencer outros da precisão científica de suas explicações) (BERLAND; REISER, 2009). É importante salientar que, no âmbito da ciência, dois ou três desses objetivos podem ser buscados simultaneamente.

Em um de seus mais influentes trabalhos, Deanna Kuhn (1991) relata um amplo estudo sobre a capacidade que pessoas comuns têm de pensar bem em situações cotidianas. Nesse estudo, ela considera que pensar é uma ação centrada em argumentar. Por isso, ao conduzi-lo, ela identificou algumas habilidades como inerentes à ação de argumentar: lidar com evidências, isto é, identificá-las, interpretá-las e utilizá-las; elaborar argumentos; elaborar teorias alternativas; contra-argumentar; e refutar.

Em nosso grupo de pesquisa optamos por, nesse contexto, usar o termo "capacidade" em vez de "habilidade", pois atribuímos ao primeiro um significado mais abrangente do que o do segundo. Em outras palavras, consideramos que cada uma das habilidades identificadas por Kuhn é uma capacidade argumentativa que envolve uma série de habilidades (MENDONÇA; JUSTI, 2009b). Nesse sentido, caracterizamos tais capacidades argumentativas como explicitado a seguir. Considerando a natureza das habilidades e o fato de algumas capacidades argumentativas serem necessárias para que outras se manifestem, algumas delas se relacionam a mais de uma capacidade. Esse relacionamento está claramente explicitado na tabela 1, que sintetiza as ideias apresentadas a seguir. 
Lidar com evidências: Em concordância com Bravo, Puig e Jiménez-Aleixandre (2009), entendemos evidências como sendo observações, fatos, sinais ou dados com os quais podemos tentar dar suporte a uma opinião. Assim, podemos afirmar que a capacidade de lidar com evidências está relacionada com:

- o metaconhecimento sobre evidências, isto é, saber o que são evidências, quais são suas principais funções e quais são os critérios que podem ser usados para avaliar a confiabilidade, a especificidade e a força das evidências; e

- as habilidades de identificar observações, fatos, sinais ou dados que podem ser usados como evidências em um determinado contexto; planejar experimentos investigativos que possam produzir evidências relativas a um dado problema; selecionar as evidências mais relevantes (isto é, específicas, suficientes e confiáveis) (JIMÉNEZ-ALEIXANDRE, 2010) para um determinado propósito; articular claramente tais evidências com uma justificativa de forma a elaborar um argumento coerente.

Elaborar argumentos: Como explicitado anteriormente, um argumento é uma afirmativa seguida de uma justificativa, isto é, de algo que objetiva dar suporte à sua veracidade. No contexto da ciência, a argumentação pode ser compreendida como um processo social de justificativa de conclusões, que se dá a partir da coordenação de dados e teorias científicas, sendo que a avaliação do conhecimento é seu aspecto central. Assim, a argumentação científica está diretamente relacionada a justificativas e persuasões (JIMÉNEZ-ALEIXANDRE; ERDURAN, 2008). A elaboração de justificativas requer a seleção de evidências a partir de dados e o estabelecimento de relações coerentes entre elas e teorias e/ou modelos aceitos no contexto em questão. Por outro lado, a persuasão requer movimentos retóricos usados na fala e na escrita com o objetivo de ponderar e dar forças às conclusões visando convencer outra pessoa de que um determinado conhecimento é melhor do que outros e/ou de que ele tem maior poder explicativo. Então, de forma mais específica, um argumento científico pode ser definido como uma afirmação devidamente subsidiada por justificativa(s) de natureza empírica e teórica. Logo, um argumento terá um maior grau de força em termos do número e da qualidade dos relacionamentos entre a afirmativa e sua(s) justificativa(s) (MENDONÇA; JUSTI, 2013a). Por isso, as habilidades requeridas para a elaboração de um argumento no contexto da ciência são: identificar evidências; diferenciar dados e/ou evidências de causas; refletir criticamente acerca de evidências; propor justificativas a partir de relacionamentos claros entre evidências e a afirmativa; elaborar analogias que possam ser usadas como (partes de) justificativas; fundamentar justificativas; usar linguagem científica adequada na expressão do argumento (MENDONÇA; JUSTI, 2009b).

Contra-argumentar. Segundo Kuhn (1991), contra-argumentar significa imaginar condições que poderiam falsificar uma ideia defendida pelo próprio sujeito. Isto acontece porque podemos identificar evidências que tanto apoiam nossas ideias quanto as contradizem. A capacidade de contra-argumentar, como 
entendida aqui, é extremamente importante na ciência, pois tenta prever (ou identificar) evidências que podem ser contrárias às nossas próprias ideias, o que tende a diminuir a probabilidade de defendermos ideias ingênuas. Isto também pode demonstrar uma concepção epistemológica menos ingênua da ciência, uma vez que decorre da aceitação de que existem limitações no conhecimento e que, portanto, devemos estar abertos a modificar nossos pensamentos. Além disso, se nós mesmos podemos prever ou identificar evidências contrárias às nossas ideias (ou que podem diminuir a força delas quando usadas em um contexto específico), outras pessoas também podem fazê-lo. Assim, se nós somos capazes de contra-argumentar, temos mais chances de preparar possíveis defesas contra os argumentos dali originados em uma discussão com outra pessoa.

A capacidade de contra-argumentar envolve, além de todas as habilidades requeridas para a elaboração de um argumento, as habilidades de: entender como um argumento pode ser contestado; analisar evidências a partir de outros pontos de vista; identificar limitações nas evidências e/ou analogias usadas na justificativa de um argumento ou, ainda, nos relacionamentos estabelecidos entre essas evidências e/ou analogias e a afirmativa original; identificar a abrangência do argumento original.

Elaborar teorias alternativas. Esta é a capacidade que um sujeito tem de imaginar uma teoria que seja diferente da que ele acredita inicialmente e igualmente plausível. Prever possíveis teorias alternativas é uma capacidade importante na prática argumentativa, pois muitas vezes vários fatores podem contribuir para um determinado resultado. $\mathrm{Na}$ ciência, muitos são os casos de coexistência de teorias alternativas em determinados contextos históricos. Em nossa vida cotidiana, ser um cidadão crítico envolve ser capaz de considerar que um problema, de qualquer natureza, pode ter (e frequentemente tem) mais de uma resposta.

Sendo assim, além de todas as habilidades listadas nos itens anteriores, a capacidade de elaborar teorias alternativas envolve a habilidade de conviver com duas ou mais explicações ou modos de ver uma situação, utilizando uma ou outra em função da melhor adequação ao contexto.

Refutar: Muito frequentemente, a prática argumentativa envolve a discussão entre dois sujeitos com opiniões distintas sobre uma mesma questão com o objetivo de se chegar a um consenso em relação à qual opinião é mais adequada. Por isso, a capacidade de um sujeito defender a sua teoria como mais correta como solução para o problema em questão, isto é, de refutar uma teoria alternativa à sua, é essencial à prática argumentativa. Assim, a refutação é importante tanto no contexto cotidiano, quando temos que decidir entre duas ou mais opções, quanto no científico, no qual a existência de controvérsia entre sujeitos ou grupos que defendem teorias alternativas uma à outra é fundamental para a construção do conhecimento.

Kuhn (1991) propõe que o sujeito pode refutar de duas maneiras: apresentando argumentos contrários à teoria do segundo sujeito (alternativa à sua) ou 
apresentando simultaneamente argumentos que mostrem a adequação de sua teoria e a inadequação da teoria do segundo sujeito. Em nossos trabalhos, consideramos também que um sujeito pode refutar quando apresenta novos argumentos que apoiam sua teoria original, pois acreditamos que esta prática constitui uma tentativa de mostrar que sua teoria original é mais adequada do que a teoria alternativa.

Independente de como ocorre a refutação, para que ela aconteça, é essencial que o sujeito use, além das habilidades mencionadas nas outras capacidades argumentativas, as habilidades de: ouvir o outro, analisar criticamente as duas posições sem interferências emocionais e utilizar a linguagem de forma a enfatizar aspectos de uma determinada teoria.

No contexto da ciência, a ocorrência de argumentação a partir da manifestação dessas capacidades é coerente com a visão de ciência expressa no início deste artigo, isto é, com a consideração de que a ciência é um empreendimento humano motivado pela curiosidade de entender o mundo por meio da produção de conhecimento científico provisório e que se modifica de forma dinâmica e não linear em diferentes contextos históricos, sociais, políticos e econômicos. Isso porque, nessa perspectiva,

- é intrinsecamente necessário justificar e julgar a adequação de modelos e teorias de acordo com os conhecimentos e evidências disponíveis; e

- a ciência tem um forte caráter social, isto é, os constructos gerados pelos cientistas estão abertos à discussão e a refutações pela comunidade científica. A fim de facilitar o estabelecimento de alguns relacionamentos explicitados em uma seção posterior, apresentamos, na tabela 1, uma síntese das habilidades relacionadas com cada uma das capacidades argumentativas. 
Tabela 1: Síntese da caracterização das capacidades argumentativas em termos das habilidades envolvidas nestas

\begin{tabular}{|c|c|}
\hline $\begin{array}{c}\text { Capacidades } \\
\text { argumentativas }\end{array}$ & Habilidades relacionadas \\
\hline Lidar com evidências & $\begin{array}{l}\text { 1. identificar observações, fatos, sinais, ou dados que podem ser } \\
\text { usados como evidências em um determinado contexto; } \\
\text { 2. planejar experimentos investigativos que possam produzir } \\
\text { evidências relativas a um dado problema; } \\
\text { 3. selecionar as evidências mais relevantes (isto é, específicas, } \\
\text { suficientes e confiáveis) para um determinado propósito; } \\
\text { 4. articular claramente tais evidências com uma justificativa de forma } \\
\text { a elaborar um argumento coerente; }\end{array}$ \\
\hline Elaborar argumentos & $\begin{array}{l}\text { (1-4)+ } \\
\text { 5. diferenciar dados e/ou evidências de causas; } \\
\text { 6. refletir criticamente acerca de evidências; } \\
\text { 7. propor justificativas a partir de relacionamentos claros entre } \\
\text { evidências e a afirmativa; } \\
\text { 8. elaborar analogias que possam ser usadas como (partes de) } \\
\text { justificativas; } \\
\text { 9. fundamentar justificativas; } \\
\text { 10. usar linguagem científica adequada na expressão do argumento; }\end{array}$ \\
\hline Contra-argumentar & $\begin{array}{l}(1-10)+ \\
\text { 11. entender como um argumento pode ser contestado; } \\
\text { 12. analisar evidências a partir de outros pontos de vista; } \\
\text { 13. identificar limitações nas evidências e/ou analogias usadas } \\
\text { na justificativa de um argumento ou, ainda, nos relacionamentos } \\
\text { estabelecidos entre essas evidências e/ou analogias e a afirmativa } \\
\text { original; } \\
\text { 14. identificar a abrangência do argumento original; }\end{array}$ \\
\hline $\begin{array}{c}\text { Elaborar teorias } \\
\text { alternativas }\end{array}$ & $\begin{array}{l}(1-14)+ \\
\text { 15. conviver com duas ou mais explicações ou modos de ver uma situação, } \\
\text { utilizando uma ou outra em função da melhor adequação ao contexto; }\end{array}$ \\
\hline Refutar & $\begin{array}{l}(1-15)+ \\
\text { 16. ouvir o outro; } \\
\text { 17. analisar criticamente as duas posições sem interferências } \\
\text { emocionais; } \\
\text { 18. utilizar a linguagem de forma a enfatizar aspectos de uma } \\
\text { determinada teoria. }\end{array}$ \\
\hline
\end{tabular}

Fonte: Elaborada pela autora.

\section{Modelagem na ciência e no Ensino de Ciências}

Nas últimas décadas, o papel central que modelos desempenham na ciência têm sido claramente reconhecido. Uma evidência disso é o grande número de filósofos, de diferentes correntes, que têm discutido esse assunto (CARTWRIGHT, 1997; 
GIERE, 1999; MORGAN; MORRISON, 1999; SUÁREZ, 1999). Apesar de eles apresentarem visões bem distintas sobre o significado de modelos (JUSTI, 2013), todos concordam que modelos são um dos principais produtos da ciência e que o processo de modelagem fundamenta a produção do conhecimento científico. A grande relevância atribuída a modelos na ciência se deve às inúmeras funções que eles podem desempenhar como, por exemplo, favorecer a visualização de entidades abstratas (GILBERT, 2008), fundamentar a proposição de explicações (GILBERT, BOULTER; RUTHERFORD, 1998), fundamentar a proposição de inferências, previsões e simulações (NERSESSIAN, 2002), dar suporte à elaboração e/ou à ampliação de teorias (MORRISON; MORGAN, 1999).

Em qualquer dicionário, um dos significados amplos atribuídos à modelagem é o de um processo de produção de modelos. Todavia, vista de uma forma mais detalhada, modelagem inclui não só a produção, mas também a validação e a utilização de modelos. Além disso, como no caso de modelos, modelagem também pode ser discutida a partir de diferentes perspectivas teóricas, incluindo a visão dos próprios cientistas envolvidos no processo. Um ótimo exemplo é o de Watson e Crick durante a proposição do modelo de dupla hélice para o DNA (WATSON, 1968). A não existência de uma visão única para como o processo de modelagem ocorre indica que, efetivamente, não existem regras gerais para a construção de modelos. Aliás, isso é coerente com uma visão ampla de ciências que reconhece as particularidades da produção de conhecimento em cada ramo da ciência (IRZIK; NOLA, 2011). Certamente, a construção de modelos é um processo dinâmico e criativo, que envolve uma grande quantidade de habilidades. Entretanto, tem sido consenso entre os pesquisadores dessa área que algumas etapas são inerentes a tal processo (JUSTI; GILBERT, 2002).

$\mathrm{Na}$ grande maioria dos casos, admite-se que a modelagem ocorre a partir de produção, teste e modificação de modelos, sem maiores detalhes sobre como cada uma dessas etapas ocorre. Na perspectiva que adotamos em nosso trabalho (e que foi desenvolvida a partir da análise de vários casos históricos e de propostas anteriores de caracterização da modelagem), consideramos que tais etapas são quatro e que cada uma delas exerce influência nas outras, como representado na figura 1.

Figura 1: Diagrama Modelo de Modelagem v. 2

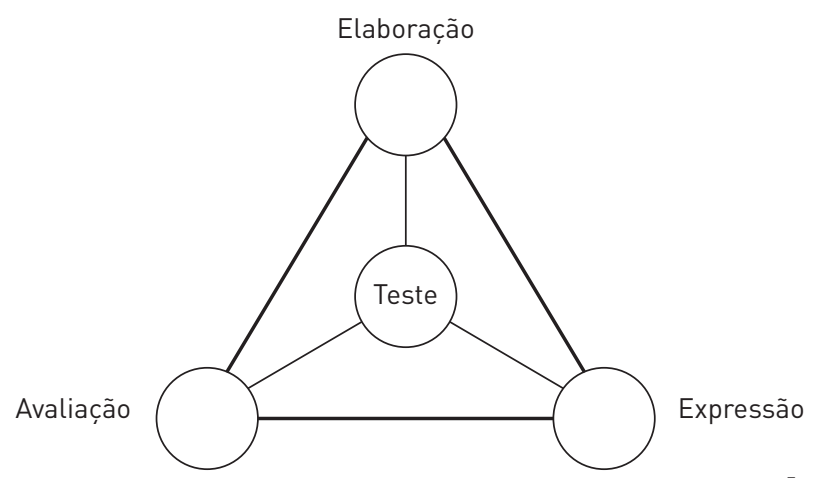

Fonte: JUSTI, 2010, p. 223. 
A fim de entendermos os relacionamentos que serão estabelecidos posteriormente, é preciso discutir o significado de cada uma dessas etapas, explicitando as subetapas que as constituem.

A elaboração de um modelo mental ocorre a partir da integração dinâmica e, às vezes, simultânea de: definir os objetivos do modelo ou entender os objetivos propostos para o modelo; obter informações sobre a entidade a ser modelada (na estrutura cognitiva prévia ou a partir de fontes externas: bibliografia, atividades empíricas etc.); definir uma analogia ou um modelo matemático para fundamentar o modelo; e integrar essas informações na proposição de um modelo. A expressão do modelo mental de forma a torná-lo acessível a outros sujeitos pode ocorrer a partir da utilização de quaisquer dos modos de representação (concreto, bidimensional, virtual, verbal, gestual, matemático). Os testes do modelo visando avaliar sua coerência com seus objetivos podem ser de dois tipos (empíricos e mentais), dependendo da entidade que está sendo modelada e das condições disponíveis para a realização dos mesmos. Finalmente, a avaliação do modelo consiste na identificação da abrangência e das limitações deste e ocorre a partir da tentativa de utilização do modelo em diferentes contextos (JUSTI; GILBERT, 2002; JUSTI, 2006).

É importante considerar também que, após a proposição do modelo mental inicial, não existe uma ordem fixa para a ocorrência das demais etapas. Por exemplo, muitas vezes o modelo mental é avaliado por testes mentais, ou mesmo tem sua abrangência analisada antes de ser expresso para que outros tenham acesso a ele. Por isso, o processo foi representado usando um tetraedro, uma figura em que todos os vértices são equidistantes e que pode ser girada em qualquer sentido sem que o entendimento da relação entre esses vértices se modifique.

Outro aspecto importante é que o diagrama Modelo de Modelagem tem algumas etapas exclusivas que o diferenciam de outras abordagens para modelagem: a expressão do modelo mental (como uma etapa distinta de sua produção) e a avaliação das abrangências e limitações do modelo proposto. Outros autores usam a palavra "avaliação", mas significando o que nós propomos ser os testes do modelo. Em outras palavras, para eles, avaliação é a análise da adequação do modelo aos seus objetivos, enquanto para nós ela é a análise da extensão em que o modelo é útil em outros contextos e de suas limitações.

No contexto do Ensino de Ciências, o envolvimento dos estudantes em atividades de modelagem caracteriza o que é chamado de ensino fundamentado em modelagem (tradução da expressão modelling-based teaching, amplamente utilizada na literatura internacional). Considerando o papel central de modelos e modelagem na ciência, vários autores (DUSCHL; ERDURAN, 1996; WHITE; FREDERIKSEN, 1998; GILBERT; BOULTER, 2000; JUSTI; GILBERT, 2003; HALLOUN, 2004; CHITTLEBOROUGH et al., 2005; CLEMENT, 2008; WINDSCHITL; THOMPSON; BRAATEN, 2008; LEHRER; SCHAUBLE, 2012; SVOBODA; PASSMORE, 2013) têm enfatizado a importância deste tipo de ensino para favorecer tanto a compreensão de ideias científicas quanto um entendimento mais amplo sobre a própria ciência. 
Muitas vezes, isso é feito apenas solicitando que os estudantes elaborem e discutam modelos para explicar um determinado fenômeno (PASSMORE; STEWART, 2002; SCHWARZ; GWEKWERERE, 2007; CLEMENT; REA-RAMIREZ, 2008; LEHRER; SCHAUBLE, 2012). Por acreditarmos que tais solicitações podem não ser suficientes para caracterizar um ensino de ciências autêntico, em nosso grupo de pesquisa, temos produzido unidades didáticas para o ensino de vários conceitos químicos e que têm sido aplicadas em situações regulares de ensino. Tais unidades didáticas são constituídas de várias atividades em cuja participação resulta o envolvimento dos estudantes em todas as etapas da modelagem (frequentemente mais de uma vez) a fim de construir seus conhecimentos (CARVALHO et al., 2006; MAIA; JUSTI, 2009; MENDONÇA; JUSTI, 2009a; 2011). Em todos os casos, os estudantes trabalham em grupos e existem momentos de discussão envolvendo toda a turma, isto é, eles interagem continuamente com seus pares e com o professor. Como consequência desse processo social de troca de ideias e experiências, os estudantes constroem seu conhecimento.

\section{ESTABELECENDO RELACIONAMENTOS ENTRE ARGUMENTAÇÃO E MODELAGEM}

Considerando o processo de modelagem como caracterizado na seção anterior, o ensino fundamentado em modelagem favorece a ocorrência de várias situações argumentativas envolvendo tanto os estudantes quanto eles e o professor. Retomando as caracterizações das capacidades argumentativas e das etapas da modelagem, passamos à discussão e à exemplificação de como as mesmas se relacionam em contextos de Ensino de Ciências fundamentado em modelagem.

\section{Relacionamentos encontrados na literatura atual}

A maioria dos autores (WINDSCHITL; THOMPSON; BRAATEN, 2008; JIMÉNEZ-ALEIXANDRE, 2010; BÖT'TCHER; MEISERT, 2011) reconhece a ocorrência de situações argumentativas durante as etapas de avaliação e modificação de modelos, uma vez que é nelas que a capacidade explicativa de diferentes modelos compete para explicar um fenômeno. De acordo com Osborne, Erduran e Simon (2004), o envolvimento de estudantes em situações argumentativas nesses contextos é algo indispensável para favorecer a tomada de decisão dos mesmos.

Por outro lado, conhecemos apenas dois trabalhos recentes que indicam a ocorrência de situações argumentativas em outras etapas do processo de modelagem. Em um deles, considerando uma estrutura focada no papel central de modelos nas etapas de elaborar questões, reconhecer padrões de dados, construir explicações e propor critérios para o julgamento de afirmativas de conhecimento, Passmore e Svoboda (2012) defendem que a argumentação ocorre em todas elas. A justificativa apresentada pelas autoras é a de que em todas essas etapas estão envolvidos um ou mais dos objetivos propostos por Berland e Reiser (2009) para a construção de explicações científicas e a participação em situações argumentativas, 
a saber: atribuição de sentido, articulação e persuasão. Isso porque, para atingir tais objetivos, os estudantes se engajam em ações como, por exemplo, interpretar fenômenos, buscar evidências relacionadas aos aspectos estudados, propor relações entre dados e modelos e avaliar modelos.

O outro trabalho que relaciona argumentação com todas as etapas da modelagem foi desenvolvido em nosso grupo de pesquisa a partir do envolvimento de estudantes no ensino fundamentado em modelagem para os tópicos ligação iônica e interações intermoleculares (MENDONÇA; JUSTI, 2013b). Nesse estudo, as atividades de ensino foram planejadas e conduzidas a partir do Diagrama Modelo de Modelagem, isto é, os estudantes tiveram a oportunidade de vivenciar todas as etapas que consideramos essenciais em processos de modelagem: produção, expressão, teste e avaliação de modelos (figura 1). A análise das situações argumentativas vividas pelos estudantes mostrou que elas se relacionavam ao desenvolvimento de todas as etapas da modelagem. Nelas, os estudantes: articularam diferentes conhecimentos na produção de seus modelos; decidiram sobre a melhor forma de representação para expressar seus modelos; discutiram e adequaram o modelo mental ao modelo expresso e vice-versa; justificaram seus modelos em relação aos objetivos definidos inicialmente ou propostos nos testes aos quais eles foram submetidos; testaram seus modelos frente a novos dados (empíricos ou teóricos); avaliaram seus modelos em termos das abrangências e limitações destes (MENDONÇA; JUSTI, 2013b). Entretanto, assim como nos estudos citados anteriormente, este estudo também não discute sobre capacidades argumentativas necessárias para a realização dessas ações, pois este não foi um dos objetivos.

\section{Novos relacionamentos}

Reanalisando os dados de nosso estudo, foi possível estabelecer alguns relacionamentos envolvendo as capacidades argumentativas claramente utilizadas pelos estudantes ao realizar cada uma das etapas da modelagem. Tais relacionamentos constituem a principal contribuição deste artigo para a literatura. Para apresentá-los, retomamos as ações necessárias para a realização de cada etapa da modelagem e apresentamos alguns exemplos que subsidiaram a proposição dos mesmos.

A etapa de produção do modelo mental envolve:

- definir os objetivos do modelo ou entender os objetivos propostos para o modelo;

- buscar informações sobre a entidade a ser modelada (na estrutura cognitiva prévia e/ou através de fontes externas: bibliografia, atividades empíricas etc.);

- selecionar e organizar as informações disponíveis tendo em mente os objetivos do modelo;

- definir uma analogia ou recurso matemático para fundamentar o modelo;

- integrar essas informações na proposição de um modelo (JUSTI; GILBERT, 2002; JUSTI, 2006). 
Como relatado em Mendonça e Justi (2013b), as atividades do ensino fundamentado em modelagem para o tema interações intermoleculares se iniciaram com a observação do comportamento distinto de duas substâncias formadas pelo mesmo tipo de ligação (iodo e grafite). Ao serem solicitados a comparar o comportamento das duas sob aquecimento, os estudantes obtiveram informações importantes sobre as entidades a serem modeladas e puderam entender o propósito dos modelos a serem elaborados: explicar o diferente comportamento das substâncias antes e depois do aquecimento. Em outras palavras, essas primeiras ações visavam, especialmente, à “atribuição de sentido" (BERLAND; REISER, 2009).

Para desempenhar tais ações, os estudantes utilizaram as seguintes capacidades argumentativas:

- lidar com evidências (tanto as experimentais, coletadas nas atividades ou solicitadas pelos estudantes ao professor, quanto suas ideias prévias sobre tópicos relacionados aos envolvidos nas atividades); e

- elaborar argumentos que relacionassem claramente as evidências (estabelecendo relações entre as evidências experimentais e os tipos de ligação presentes nas substâncias) e que fundamentassem justificativas para seu modelo. Então, a realização da etapa de produção do modelo mental inicial requereu as habilidades 1 a 10 da tabela 1 . Isto foi evidenciado acompanhando as discussões nos grupos, que podem ser sintetizadas em alguns dos argumentos expressos pelos estudantes:

- "No iodo há rompimento de ligaçoes porque sua temperatura de fusão é baixa. No grafite há apenas vibração das partículas porque sua temperatura de fusão é elevada." (Elaboração e expressão do modelo 1 do grupo 2, situação na qual os estudantes selecionaram evidências relevantes, analisaram criticamente o significado delas e as articularam coerentemente com seus conhecimentos prévios, elaborando um argumento expresso em linguagem clara.)

- "A ligação no iodo é covalente porque cada átomo tem sete elétrons." (Justificativa para o tipo de ligação presente no modelo 1 do grupo 2, situação na qual os estudantes fundamentaram uma justificativa de um argumento.)

A etapa de expressão do modelo mental envolve:

- visualizar o modelo mental;

- utilizar quaisquer dos modos de representação (concreto, bidimensional, virtual, verbal, gestual, matemático) para representar o modelo;

- adequar o modelo expresso ou o modelo mental a partir de comparações entre eles e/ou com o objetivo do modelo (JUSTI; GILBERT, 2002; JUSTI, 2006).

Ao realizar tais ações, os estudantes utilizaram algumas das habilidades das capacidades de elaborar argumentos, no contexto de justificativa dos modos e/ ou códigos de representação utilizados na expressão do modelo; e elaborar teorias alternativas que, nesse contexto, seriam diferentes modelos para a mesma entidade (habilidades 8, 9, 10 e 15 na tabela 1 ). 
Em nossos dados, isso foi observado, por exemplo, quando os estudantes: justificaram o uso de materiais diferentes (bolas de isopor e massas de modelar de cores diferentes) para representar átomos e moléculas distintas; expressaram um mesmo modelo usando modos de representação diversos: concreto, bidimensional (desenho) e verbal; recorreram a cada um desses modelos expressos com pertinência em momentos distintos (isto é, para explicar aspectos distintos ou evidenciar detalhes específicos das representações); e explicitaram um raciocínio analógico elaborado a partir de uma representação para a proposição de um modelo ("Se iodo é representado por $I_{2}$, grafite é representado por $C_{2}$." - elaboração e expressão do modelo 1 do grupo 4).

A etapa de teste dos modelos requer:

- planejar e conduzir experimentos mentais;

- planejar e conduzir experimentos empíricos;

- analisar criticamente os resultados dos testes;

- modificar ou rejeitar o modelo testado (JUSTI; GILBERT, 2002; JUSTI, 2006). Tais ações se relacionam aos objetivos de "atribuição de sentido" e "articulação", caso o sujeito esteja trabalhando individualmente. Quando o modelo está sendo elaborado em grupo, elas também podem envolver a "persuasão" de sujeitos do próprio grupo.

Em nosso estudo, após a elaboração do modelo inicial para explicar a diferença no comportamento das substâncias iodo e grafite, os estudantes conduziram experimentos mentais e/ou empíricos a fim de analisar seus modelos iniciais frente a novos dados empíricos observados na reação entre iodo e amido. Dependendo dos resultados desses testes, seus modelos foram reformulados ou abandonados. Para tanto, os estudantes utilizaram as capacidades de:

- lidar com evidências, principalmente identificando e interpretando as novas evidências experimentais a partir de seus conhecimentos prévios;

- elaborar argumentos a favor de seus novos modelos após a socialização destes para toda a turma;

- contra-argumentar, ao pensar em argumentos distintos dos originais e, a partir daí, propor experimentos mentais por meio dos quais seus modelos pudessem ser testados; e

- elaborar teorias alternativas, aspecto observado especialmente na discussão entre estudantes de um mesmo grupo durante a reformulação de modelos. Isso significa que, ao realizar os diversos testes de seus modelos, os estudantes utilizaram as habilidades argumentativas 1 a15 da tabela 1.

A etapa de avaliação do modelo requer:

- identificar as limitações do modelo a partir da contraposição do mesmo com seu(s) objetivo(s);

- identificar a abrangência do modelo a partir da tentativa de utilização do mesmo em diferentes contextos;

- convencer outros da validade do modelo produzido (JUSTI; GILBERT, 2002; JUSTI, 2006). 
Como esta é uma etapa muito complexa, ela pode requerer a utilização de todas as capacidades argumentativas, em especial a de refutar visando a persuasão. Nossos dados mostram que, considerando os resultados dos sucessivos testes realizados com seus modelos e as discussões envolvidas dos mesmos, os estudantes elaboraram argumentos bem justificados para apresentar e defender a abrangência de seus modelos. Isto foi feito das três possíveis maneiras mencionadas anteriormente, isto é: apresentando argumentos contrários a um modelo distinto defendido por outro grupo ("O modelo $\mathrm{NaCl}$ molécula' não explica a temperatura de fusão, porque não mostra todas as particulas próximas e com atrações fortes.” (grupo 2)); apresentando argumentos cujas justificativas mostravam a adequação do modelo defendido pelo grupo e a inadequação de modelos distintos defendidos por outros grupos simultaneamente ("Modelo em rede explica por que as partículas estão interagindo próximas umas às outras. Modelo $\mathrm{NaCl}$ molécula' é incoerente porque, se as interações entre as particulas fossem iguais, elas deveriam se unir." (grupo 4)); e apresentando argumentos que destacavam as qualidades do modelo defendido pelo grupo, sendo que algumas vezes isso era feito enfatizando que aquelas qualidades eram exclusivas do modelo defendido pelo grupo ("Nosso modelo é plausível porque mostra partículas próximas, com várias atrações, e cuja força varia com a distância." (grupo 4)).

É importante enfatizar que, como todos os argumentos utilizados aqui como exemplos foram expressos pelos estudantes em situações em que eles estavam aprendendo os conceitos envolvidos pela primeira vez, muitos deles contêm ideias distintas daquelas que se esperava que eles aprendessem. Tal fato não invalida os relacionamentos aqui discutidos.

\section{CONSIDERAC̣ÕES FINAIS}

Considerando uma situação regular de ensino fundamentado em modelagem para os temas ligação iônica e interações intermoleculares, assim como alguns constructos teóricos sobre argumentação e modelagem, foi possível concluir que a utilização das habilidades relacionadas à argumentação favoreceu a realização de etapas específicas da modelagem, ou, de maneira inversa, que a participação em atividades de modelagem requer a utilização de todas as habilidades relacionadas à argumentação. Apesar de tais relacionamentos terem sido estabelecidos apenas a partir da análise de um conjunto de dados empíricos que envolvem a aprendizagem de temas químicos bastante abstratos, acreditamos que eles podem ser generalizados para outras situações de ensino fundamentado em modelagem. Isso porque análises de outros conjuntos de dados (relativos a situações de ensino de outros temas, sendo alguns menos abstratos) que estão sendo realizadas atualmente têm apontado para a existência dos mesmos relacionamentos. Isto corrobora nossa premissa de que, na ciência, as práticas de argumentar e modelar são indissociáveis e aponta para o ensino fundamentado em modelagem como uma das alternativas para se promover um Ensino de Ciências autêntico (como caracterizado no início deste trabalho). 
Ao mesmo tempo, o estabelecimento dos relacionamentos aqui apresentados suscita novas indagações. No contexto investigado em nosso estudo, o principal objetivo era o de que os estudantes aprendessem os temas ligação iônica e interações intermoleculares a partir da participação ativa em atividades de ensino fundamentado em modelagem. Nesse contexto, não ocorreu ensino explícito de argumentação, isto é, a professora não discutiu sobre os elementos de um bom argumento, nem destacou as capacidades envolvidas na elaboração e no uso deles (apesar de ter favorecido várias situações nas quais tais capacidades pudessem ser utilizadas). Se o contexto de ensino for modificado (por exemplo, se o tema a ser ensinado for de natureza sociocientífica e/ou se ocorrer ensino explícito de argumentação), os relacionamentos aqui estabelecidos continuam válidos? Por quê? Como eventuais diferenças podem ser explicadas?

Com certeza, estas e outras questões serão investigadas no futuro visando contribuir para gerar e consolidar conhecimentos sobre a utilização das práticas científicas argumentar e modelar no Ensino de Ciências que possam, por exemplo, subsidiar diretrizes para ações docentes envolvidas no planejamento e na condução de situações de Ensino de Ciências autêntico nessa perspectiva.

\section{AGRADECIMENTOS}

A Paula Cristina Cardoso Mendonça, por introduzir o tema argumentação em nosso grupo de pesquisa e pelas valiosas discussões sobre argumentação e modelagem ocorridas nos últimos anos; ao $\mathrm{CNPq}$, pelo apoio financeiro para a realização das pesquisas que originaram este trabalho; e aos organizadores do Workshop "Argumentação e Ensino de Ciências", pelo convite, que resultou na oportunidade de elaborar o trabalho aqui apresentado.

\section{NOTA}

${ }^{1}$ Para maiores detalhes, ver MENDONÇA; JUSTI, 2013 a.

\section{REFERÊNCIAS}

BERLAND, L. K.; REISER, B. J. Making Sense of Argumentation and Explanation. Science Education, v. 93, n. 1, p. 26-55, 2009.

BÖTTCHER, F.; MEISERT, A. Argumentation in Science Education: A Model-based Framework. Science \& Education, v. 20, n. 2, p. 103-140, 2011.

BRAVO, B.; PUIG, B.; JIMÉNEZ-ALEIXANDRE, M. P. Competencias en el uso de pruebas en argumentación. Educación Química, v. 20, n. 2, p. 126-131, 2009.

CARAGNETTO, A. R. Argument to Foster Scientific Literacy: A Review of Argument Interventions in K-12 Science Contexts. Review of Educational Research, v. 80, n. 3, p. 336-371, 2010. 
CARTWRIGHT, N. Models: The Blueprints for Laws. Philosophy of Science, v. 64, n. Supplement, p. S292-S303, 1997.

CARVALHO, N. B.; QUEIROZ, A.S.; JUSTI, R.; BASTOS, D.R. Elaboração de uma atividade sobre interações intermoleculares fundamentada no processo de modelagem. Trabalho apresentado no XIII Encontro Nacional de Ensino de Química, 2006, Campinas. 24-27 de julho.

CHINN, C. A.; MALHOTRA, B. A. Epistemologically Authentic Inquiry in Schools: A Theoretical Framework for Evaluating Inquiry Tasks. Science Education, v. 86, n. 2, p. 175-218, 2002.

CHITTLEBOROUGH, G. D.; TREAGUST, D. F.; MAMIALA. T. L; MOCERINO, M. Students' perceptions of the role of models in the process of science and in the process of learning. Research in Science \& Technological Education, v. 23, n. 2, p. 195-212, 2005.

CLEMENT, J. J. Model Based Learning and Instruction in Science. In: CLEMENT, J. J.; REARAMIREZ, M. A. (Ed.). Model Based Learning and Instruction in Science. Dordrecht: Springer, 2008. p. 1-9.

CLEMENT, J. J.; REA-RAMIREZ, M. A. Model Based Learning and Instruction in Science. Dordrecht: Springer, 2008.

DUSCHL, R.; ELLENBOGEN, K. Argumentation and Epistemic Criteria: Investigating Learners' Reasons for Reasons. Educación Química, v. 20, n. 2, p. 111-118, 2009.

DUSCHL, R.; ERDURAN, S. Modelling the Growth of Scientific Knowledge. In: WELFORD, G.; OSBORNE, J.; SCOTT, P. (Ed.). Research in Science Education in Europe: Current Issues and Themes. London: Falmer, 1996. p. 153-165.

GIERE, R. N. Using Models to Represent Reality. In: MAGNANI, L.; NERSESSIAN, N. J.; THAGARD, P. (Ed.). Model-Based Reasoning in Scientific Discovery. New York: Kluwer and Plenum, 1999. p. 41-57.

GILBERT, J. K. Models and Modelling: Routes to a more authentic science education. International Journal of Science and Mathematics Education, v. 2, p. 115-130, 2004.

Visualization: An emergent field of practice and enquiry in science education. In: GILBERT, J. K.; REINER, M., et al. (Ed.). Visualization: Theory and Practice in Science Education: Springer, 2008. p. 3-24.

GILBERT, J. K.; BOULTER, C. J. Developing Models in Science Education. Dordrecht: Kluwer, 2000.

GILBERT, J. K.; BOULTER, C. J.; RUTHERFORD, M. Models in explanations, Part I: Horses for courses? International Journal of Science Education, v. 20, n. 1, p. 83-97, 1998.

HALLOUN, I. A. Modeling Theory in Science Education. Dordrecht: Kluwer, 2004.

IRZIK, G.; NOLA, R. A Family Resemblance Approach to the Nature of Science for Science Education. Science \& Education, v. 20, n. 7-8, p. 591-607, 2011.

JIMÉNEZ-ALEIXANDRE, M. P. 10 Ideas Clave: Competencias en argumentación y uso de pruebas. Barcelona: Graó, 2010.

. Determinism and Underdetermination in Genetics: Implications for Students' Engagement in Argumentation and Epistemic Practice. Science \& Education, v. 23, n. 2, p. 465-484, 2012.

JIMÉNEZ-ALEIXANDRE, M. P.; ERDURAN, S. Argumentation in Science Education: An Overview. In: ERDURAN, S. e JIMÉNEZ-ALEIXANDRE, M. P. (Ed.). Argumentation in Science Education: Perspectives from classroom-based research. Dordrecht: Springer, 2008. p. 3-27.

JUSTI, R. La Enseñanza de Ciencias Basada en la Elaboración de Modelos. Enseñanza de las Ciencias, v. 24, n. 2, p. 173-184, 2006.

. Modelos e Modelagem no Ensino de Química. In: SANTOS, W. L. P. e MALDANER, O.

A. (Ed.). Ensino de Química em Foco. Ijuí, RS: Ed. Unijuí, 2010. p. 209-230.

. Models and Representations: Additional theoretical discussions in the science education context. Trabalho apresentado na X European Science Education Research Association Conference, Nicosia, Cyprus, 2-9 September. 2013.

JUSTI, R.; GILBERT, J. K. Modelling, teachers' views on the nature of modelling, implications for the education of modellers. International Journal of Science Education, v. 24, n. 4, p. 369-387, 2002.

. Models and Modelling in Chemical Education. In: GILBERT, J. K.; DE JONG, O.; JUSTI, R.; TREAGUST, D. F.; VAN DRIEL, J. H. (Ed.). Chemical Education: Towards Research-based Practice. Dordrecht: Kluwer, 2003. p. 47-68. 
KUHN, D. The Skills of Argument. New York: Cambridge University, 1991.

LEHRER, R.; SCHAUBLE, L. Seeding Evolutionary Thinking by Engaging Children in Modeling Its Foundations. Science Education, v. 96, n. 4, p. 701-724, 2012.

MAIA, P. F.; JUSTI, R. Learning of Chemical Equilibrium through Modelling-Based Teaching. International Journal of Science Education, v. 31, n. 5, p. 603-630, 2009.

MENDONÇA, P. C. C.; JUSTI, R. Favorecendo o aprendizado do modelo eletrostático: Análise de um processo de ensino de ligação iônica fundamentado em modelagem Parte I. Educación Química, v. 20 , n. E, p. 282-293, 2009a.

Proposição de um Instrumento para Avaliação de Habilidades Argumentativas - Parte I - Fundamentos

Teóricos. Trabalho apresentado no VII Encontro Nacional de Pesquisa em Educação em Ciências, Florianópolis, 08-13 de novembro 2009b.

. Contributions of the Model of Modelling Diagram to the Learning of Ionic Bonding:

Analysis of a Case Study. Research in Science Education, v. 41, n. 4, p. 479-503, 2011.

Ensino-Aprendizagem de Ciências e Argumentação: Discussões e Questões Atuais. Revista

Brasileira de Pesquisa em Educacão em Ciências, v. 13, n. 1, p. 187-216, 2013 a.

The Relationships between Modelling and Argumentation from the Perspective of the Model of Modelling Diagram. International Journal of Science Education, v. 35, n. 14, p. 2007-2034, 2013 b.

MORGAN, M. S.; MORRISON, M. Models as Mediators: Perspectives on Natural and Social Science. Cambridge: Cambridge University Press, 1999.

MORRISON, M.; MORGAN, M. S. Models as mediating instruments. In: MORGAN, M. S. ; MORRISON, M. (Ed.). Models as Mediators: Perspectives on Natural and Social Science. Cambridge: Cambridge University Press, 1999. p. 10-37.

NERSESSIAN, N. J. The cognitive basis of model-based reasoning in science. In: CARRUTHERS, P.; STICH, S.; SIEGAL, M. (Ed.). The cognitive basis of science. Cambridge: CUP, 2002. p. 133-153.

OSBORNE, J.; ERDURAN, S.; SIMON, S. Enhancing the Quality of Argumentation in School Science. Journal of Research in Science Teaching, v. 41, n. 10, p. 994-1020, 2004.

PASSMORE, C. M.; STEWART, J. Modeling Approach to Teaching Evolutionary Biology in High Schools. Journal of Research in Science Teaching, v. 39, n. 3, p. 185-204, 2002.

PASSMORE, C. M.; SVOBODA, J. Exploring Opportunities for Argumentation in Modelling Classrooms. International Journal of Science Education, v. 34, n. 10, p. 1535-1554, 2012.

SCHWARZ, C. V.; GWEKWERERE, Y. N. Using a Guided Inquiry and Modeling Instructional Gramework (EIMA) to Support Preservice K-8 Science Teaching. Science Education, v. 91, n. 1, p. 158-186, 2007.

SUÁREZ, M. Theories, Models, and Representations. In: MAGNANI, L.; NERSESSIAN, N. J.; THAGARD, P. (Ed.). Model-Based Reasoning in Scientific Discovery. New York: Kluwer Academic and Plenum Plublishers, 1999. p. 75-83.

SVOBODA, J.; PASSMORE, C. M. The Strategies of Modeling in Biology Education. Science \& Education, v. 22, n. 1, p. 119-142, 2013.

WATSON, J. D. The Double Helix - The Discovery of the Structure of DNA. London: Orion Books, 1968. WHITE, B. Y.; FREDERIKSEN, J. R. Inquiry, Modeling, and Metacognition: Making Science Accessible to All Students. Cognition and Instruction, v. 16, n. 1, p. 3-119, 1998.

WINDSCHITL, M.; THOMPSON, J.; BRAATEN, M. Beyond the Scientific Method: Model-Based Inquiry as a New Paradigm of Preference for School Science Investigations. Science Education, v. 92, n. 5, p. 941-967, 2008. 